\title{
Section Four: Memoirs, Resources, and Insights About Donald A.B. Lindberg M.D.
}

\author{
Robert A. LOGAN Ph.D. ${ }^{1}$ \\ U.S. National Library of Medicine (retired)
}

\begin{abstract}
Section four provides additional insights into Donald A.B. Lindberg M.D.'s life, character, interests, and passions. It includes 20 memoirs, a few of his photographs, a Resource Guide, and an essay about the influence of his home library and leadership traits. Section four's 20 memoirs are brief, more colloquial, and sometimes personal. The memoirs discuss Dr. Lindberg's interactions with family, lifelong friends, biomedical informatics colleagues, and U.S. National Library of Medicine (NLM) peers. The Resource Guide, photos, and essay yield other insights and assist readers who wish to learn more about Dr. Lindberg.
\end{abstract}

Keywords: Donald A.B. Lindberg M.D., U.S. National Library of Medicine, memoirs, leadership

\section{Introduction}

Section four provides additional insights into Donald A.B. Lindberg M.D.'s life, character, interests, and passions. It includes 20 memoirs, a few of his photographs, a Resource Guide, and an essay about the influence of his home library and leadership traits.

Section four differs from the book's other sections, which describe Dr. Lindberg's contributions to biomedical informatics, worldwide access to scientific and health information, and outreach to the underserved. The tribute by NLM's Board of Regents on his retirement summarized Dr. Lindberg's professional impact as such: '(Dr. Lindberg) fundamentally (changed) the way biomedical knowledge and health information is collected, organized, and made available for public use - in small villages in Alaska and Mali as well as in laboratories of Nobel prizewinners. He has therefore empowered the public and transformed the conduct of research, the education of students, and the care of patients.'

In contrast, section four's 20 memoirs are brief, more conversational, and sometimes personal. The memoirs discuss Dr. Lindberg's interactions with family, lifelong friends, biomedical informatics colleagues, and U.S. National Library of Medicine (NLM) peers. The Resource Guide, photos, and essay yield additional insights and assists readers who wish to learn more about Dr. Lindberg.

While it is a challenge to portray the persona of a multi-dimensional person (who also was a disciplinary pioneer and a public figure), the contributions in this section enable readers to glimpse Dr. Lindberg's character and why he was highly respected. As

\footnotetext{
${ }^{1}$ Corresponding author: logrob@gmail.com
} 
Mark Twain wrote: 'there is a great deal of human nature in people' - and Dr. Lindberg was not an exception.

That said, the memoirs raise a few aspects of Dr. Lindberg's personality and character that might surprise people who did (and did not) have the opportunity to know him.

\section{Memoirs - Family}

The seven memoirs about Dr. Lindberg from family members include contributions from two sons, his grandson, two daughters-in-law, brother/sister-in-law, and brother. The memoirs focus on Dr. Lindberg as a father, grandfather, father-in-law, brother, brotherin-law, and family leader. Each memoir provides a snapshot of Dr. Lindberg's interactions that weave a tapestry of remembrances and insights.

For example, Jon Lindberg (Dr. Lindberg's son) writes about childhood fun on his family's Missouri farm, trips on horseback in several locations, and meeting a Nobel laureate [1]. Jon explains one of his father's gifts was the ability to communicate with persons from diverse backgrounds [1]. Jon explains Dr. Lindberg looked forward to conversations with the sanitation workers who collected the trash at the Lindberg's Maryland home as much as he enjoyed talking to the President of the United States [1].

Don Lindbergh (Dr. Lindberg's son) writes how his father's personality turned more demonstrative during a New York City visit [2]. After watching his father try to get routine assistance from New York City cab drivers, hotel desk workers, and waitresses, Don Lindbergh notes he became more self-assertive [2]. Don explains how his father persuaded the family's horses to gallop at their Missouri farm and notes Dr. Lindberg's nightly readings to his then-young sons [2].

Chris Lindberg (Dr. Lindberg's grandson) emphasizes his respect for the leadership Dr. Lindberg provided in the U.S.' cultural/professional transition to the digital age [3]. Chris also mentions the time he spent with Dr. Lindberg in a favorite family car, eating in a drive-in restaurant, and hearing him walk up the wooden stairs in his house after a long day at NLM [3].

Kelly McGee (Dr. Lindberg's daughter-in-law) introduces how Dr. Lindberg stayed informed and his enduring enthusiasm for the arts and culture [4]. McGee explains she began to understand Dr. Lindberg's professional influence on a trip to a biomedical informatics seminar at Woods Hole, MA. [4].

Amy Lindberg (Dr. Lindberg's daughter-in-law) recounts Dr. Lindberg's encouragement during a family boat journey in the eastern U.S. [5]. Amy explains how Dr. Lindberg enjoyed sharing family responsibilities. Amy details how she stood her ground, took charge, and contributed to the role as the craft's navigator [5].

Roy Musick M.D. and Linda Musick, Dr. Lindberg's brother and sister-in-law, note his influence on their professional life and hobbies. Dr. Musick suggests he would not have become a successful physician (who practiced in Northern California) if Dr. Lindberg had not persuaded him to try medical school [6]. Dr. Musick describes attending a memorable autopsy while still in medical school with Dr. Lindberg's enthusiastic coaching [6]. Similarly, Linda Musick explains how her interest in photography grew as a result of Dr. Lindberg's keenness and guidance [6]. She recalls Dr. Lindberg's emotional intensity during a visit to take photographs at Gettysburg, the site of a decisive battle during the U.S. Civil War [6]. 
Finally, in a narrative about growing up in Brooklyn, Charlie Lindberg (Dr. Lindberg's brother) writes about their childhood home, love of inexpensive cars, and assisting their father. He was an architect [7]. Charlie depicts Flatbush life and contrasts its affordability and degrees of freedom with contemporary urban society [7]. Charlie also compares how he and his brother spent one of the most difficult days in contemporary U.S. history - September 11, 2001 [7].

\section{Memoirs - Life-long Friends}

The four memoirs from life-long friends include contributions from Frederick L. Edelman M.D., Carl M. Pellman M.D., Tyler Abell J.D., and Charles Kalina MBA.

Dr. Edelman writes he probably met Dr. Lindberg in kindergarten at Brooklyn (NY) PS 197. Edelman notes how he, his wife, and the Lindbergs once received an appreciative salute for a lively conversation from a diner at a different restaurant table [8]! Edelman also introduced Dr. Lindberg to Carl Pellman during their senior year in high school [8].

Dr. Pellman, Dr. Lindberg's classmate at Amherst and at the College of Physicians and Surgeons at Columbia University, explains how they initially bonded from a mutual interest in experimental embryology [9]. Pellman adds he and Dr. Lindberg enjoyed the fun atmosphere created by Amherst professor Emile Shotte [9]. Pellman recalls that he and Dr. Lindberg continued working with Prof. Shotte to regenerate limbs in frogs and newts after college [9].

Abell, Dr. Lindberg's roommate at Amherst, provides insights into their colorful college life and undergraduate experiences. Abell suggests many of Dr. Lindberg's hobbies (including travel, boating, opera, reading, collecting books and music, photography, technology, and interest in science and the humanities) were formed by his 21st birthday [10]. Abell notes the friends Dr. Lindberg made at Amherst advanced his curiosity and wide range of interests early on and throughout his life [10].

Kalina, who was both Dr. Lindberg's childhood friend and an NLM colleague, notes how they worked together to prevent the deterioration of NLM's physical media, including optical discs and non-acid-free paper [11]. Kalina suggests Dr. Lindberg provided leadership in a then-vacuum of concern about the surprisingly short life span of paper-based products, which impacted the U.S. Congress's decision to require acidfree paper for future federal governmental use [11].

\section{Memoirs - Biomedical Informatics Colleagues}

Three long-time biomedical informatics colleagues, Randolph Miller M.D., Joyce Mitchell Ph.D., and Rashid Bashshur Ph.D., provide memoirs about Dr. Lindberg's contributions as a peer and a mentor.

Dr. Miller outlines Dr. Lindberg's contributions to the development of biomedical informatics as a discipline and Dr. Lindberg's impact on Miller's career [12]. Miller also stresses the significant personal and social contributions of Mary Lindberg (Dr. Lindberg's wife) to the field of biomedical informatics and NLM [12]. Miller, an Emeritus Professor at Vanderbilt University School of Medicine, is a key contributor to the book's first section and is one of the book's four co-editors [12]. 
Dr. Mitchell explains Dr. Lindberg's role as her career mentor, which began as a post-doctoral student through becoming the chair of the bioinformatics department at the University of Utah [13]. Mitchell also provides a mise en scene account of the sobering developments during the NLM Board of Regents meeting on September 11, 2001, and how the ensuing decisions to continue NLM's services reflected the Library's prominence and progress [13]. The aforementioned memoir from Charlie Lindberg reflects on the events he experienced across the Potomac River in Virginia on the same morning [13].

Dr. Bashshur describes how Dr. Lindberg and NLM supported Bashshur's work on the use of telemedicine in disaster preparedness/response, and to facilitate large-scale clinical trials [14]. Bashshur notes Dr. Lindberg and NLM also assisted Bashshur's efforts to write a book on the history of telemedicine [14]. Bashshur emphasizes Dr. Lindberg was a steady and reliable source of career support, guidance, and wisdom [14]. He suggests Dr. Lindberg's unique qualities and extraordinary influence helped Bashshur achieve his potential as a health care professional [14].

\section{Memoirs - NLM Colleagues}

Six memoirs are provided by persons with diverse backgrounds who worked with Dr. Lindberg at NLM: Dylan Rain Tree J.D.; Tom West Ph.D.; Janet Laylor B.A.; George Thoma Ph.D.; Steven Phillips M.D.; and Pat Carson. Their memoirs attest to the personal impact of the work environment and atmosphere at NLM that Dr. Lindberg cultivated.

Similar to Joyce Mitchell and Rashid Bashshur, the memoir from Dylan Rain Tree J.D. extols Dr. Lindberg as a mentor [15]. Akin to the memoir from Dr. Musick, Rain Tree notes how Dr. Lindberg persuaded him to become an attorney and devote his practice to Native American issues [15]. Rain Tree, who is a Native American, now practices law in Fresno, CA. He assisted in the development and expansion of the Native Voices exhibition at NLM.

Dr. Lindberg supported West's writing about the talents of dyslexic individuals and the importance of visual thinking in the history of medicine and science [16]. West notes his admiration of Dr. Lindberg's abilities to attract talented and creative people for his staff, NLM's Board of Regents, and NLM's diverse, inventive projects [16]. West recalls hearing Marc Andreessen, the founder of Netscape and the Silicon Valley venture-capital firm Andreessen Horowitz, speak at NLM on the day he distributed the initial software to access Mosiac, the world's first Internet browser [16].

Laylor adds her gratitude for Dr. Lindberg's and NLM's stellar support during her gender transition [17]. Laylor explains the tolerance exhibited to her was not unique and reflected an underlying forbearance at NLM for people, ideas, diversity, and innovation [17]. She suggests the latter was an essential element of Dr. Lindberg's successful 31year tenure as NLM's Director [17].

Dr. Thoma applauds Dr. Lindberg's breath of vision and support for innovative projects at NLM, such as machine learning [18]. Thoma, who was the chief of NLM's Communications Engineering Branch (within the Lister Hill National Center for Biomedical Communications) for 34 years, underscores Dr. Lindberg's backing for the branch's document imaging and optical character recognition work to extract bibliographic data from scanned medical journal articles [18]. The latter initiative ensured MEDLINE, the leading international source of access to medical literature, could be kept up to date. Among other examples, Thoma notes Dr. Lindberg's 
enthusiasm for Turning the Pages. This branch project facilitates the 'touching and turning' of a book's (scanned) pages and provides readers with a realistic look and feel of the original text [18]. Thoma additionally salutes Dr. Lindberg's efforts to create a family atmosphere for NLM's employees [18].

Dr. Phillips explains that he appreciated Dr. Lindberg's biomedical informatics contributions for several years before they met [19]. Phillips notes how he became involved at NLM as a member of the Board of Regents and later as the Deputy Director, and the director of NLM's Specialized Information Services Division [19]. Phillips adds an entertaining story about when he and Dr. Lindberg took off to cruise the Potomac River during an oppressive Washington D.C. heatwave [19].

Finally, Pat Carson (Dr. Lindberg's long-standing executive assistant) describes the behind-the-scenes work and effort needed to host many of NLM's social occasions and special visitors [20]. Carson amusingly recounts how she arranged Dr. and Mrs. Lindberg's Louis XIV/Marie Antoinette costumes for a well-received costume party that accompanied the opening of NLM's Frankenstein exhibition [20]. Carson underscores that despite a constant array of activities at NLM, it was fun to work with and support Dr. Lindberg (as well as Mary Lindberg) [20].

\section{Other Contributions in Section Four}

In addition to the memoirs in section four, an essay by the current author explains the influence of Dr. Lindberg's home library. It discusses two of his leadership traits: the cultivation of discovery and project development in educational administration and the need for leaders to determine and act in the greater public interest [21]. The chapter suggests the latter two traits defined Dr. Lindberg's NLM leadership [21].

A Resource Guide is provided to help readers learn more about Dr. Lindberg and NLM's activities during his 31-year tenure as director [22]. Among other things, the Resource Guide contains some tributes written after Dr. Lindberg's death, accolades received when Dr. Lindberg's retired from the U.S. National Library of Medicine, resources about Dr. Lindberg's career and contributions, manuscripts authored by Dr. Lindberg, and links to NLM annual reports written during Dr. Lindberg's helm [22].

Section four adds several photographs selected by Mary Lindberg, illustrating Dr. Lindberg's artistic/creative side [23]. A collection of Dr. Lindberg's photos, including some of the images selected herein, surrounded the walls of NLM's Lindberg room (where the Board of Regents and senior staff members met) for many years.

Overall, the contributions in section four furnish informal snapshots into Dr. Lindberg's character, interests, and contributions. They yield wide-ranging insights into Dr. Lindberg's persona and interactions with family, friends, and colleagues. Section four also provides a 'tell me more' educational resource about Dr. Lindberg, which was a service he championed for health professionals and the public throughout his career. The aggregate contributions provide a collage of Dr. Lindberg's family and professional life, leadership skills, and inspiring contributions.

Acknowledgements: Mary Lindberg contributed significantly to the selection of the memoir authors and to the planning of section four. 


\section{References}

[1] Lindberg JEM. Memories of my father. In: Humphreys BL, Logan RA, Miller RA, Siegel ER, editors. Transforming biomedical information and health information access: Don Lindberg and the U.S. National Library of Medicine. Amsterdam: IOS Press; 2021.

[2] Lindbergh DAB. Learning from my dad: Donald A.B. Lindberg M.D. In: Humphreys BL, Logan RA, Miller RA, Siegel ER, editors. Transforming biomedical information and health information access: Don Lindberg and the U.S. National Library of Medicine. Amsterdam: IOS Press; 2021.

[3] Lindberg C. Icon. In: Humphreys BL, Logan RA, Miller RA, Siegel ER, editors. Transforming biomedical information and health information access: Don Lindberg and the U.S. National Library of Medicine Amsterdam: IOS Press; 2021.

[4] McGee K. Donald A.B. Lindberg: uomo universal. Lindberg In: Humphreys BL, Logan RA, Miller RA, Siegel ER, editors. Transforming biomedical information and health information access: Don Lindberg and the U.S. National Library of Medicine. Amsterdam: IOS Press; 2021.

[5] Lindberg A. Don Lindberg: helping others thrive. In: Humphreys BL, Logan RA, Miller RA, Siegel ER, editors. Transforming biomedical information and health information access: Don Lindberg and the U.S. National Library of Medicine. Amsterdam: IOS Press; 2021.

[6] Logan RA. Don Lindberg's diverse influence: an interview with Roy Musick M.D. and Linda Musick. In: Humphreys BL, Logan RA, Miller RA, Siegel ER, editors. Transforming biomedical information and health information access: Don Lindberg and the U.S. National Library of Medicine. Amsterdam: IOS Press; 2021.

[7] Logan RA. Growing up with my brother, Doctor Don: interview with Charles Lindberg. In: Humphreys BL, Logan RA, Miller RA, Siegel ER, editors. Transforming biomedical information and health information access: Don Lindberg and the U.S. National Library of Medicine. Amsterdam: IOS Press; 2021.

[8] Edelman FL. Donald A.B. Lindberg: a lifelong friend. In: Humphreys BL, Logan RA, Miller RA, Siegel ER, editors. Transforming biomedical information and health information access: Don Lindberg and the U.S. National Library of Medicine. Amsterdam: IOS Press; 2021.

[9] Pellman CM. Don Lindberg: a seven-decade friendship. In: Humphreys BL, Logan RA, Miller RA, Siegel ER, editors. Transforming biomedical information and health information access: Don Lindberg and the U.S. National Library of Medicine. Amsterdam: IOS Press; 2021.

[10] Logan RA. At Amherst and afterwards: interview with Tyler Abell about Don Lindberg. In: Humphreys BL, Logan RA, Miller RA, Siegel ER, editors. Transforming biomedical information and health information access: Don Lindberg and the U.S. National Library of Medicine. Amsterdam: IOS Press; 2021.

[11] Kalina C. Don Lindberg: best friend and colleague. In: Humphreys BL, Logan RA, Miller RA, Siegel ER, editors. Transforming biomedical information and health information access: Don Lindberg and the U.S. National Library of Medicine. Amsterdam: IOS Press; 2021.

[12] Miller RA. Remembering Don Lindberg: two letters. In: Humphreys BL, Logan RA, Miller RA, Siegel ER, editors. Transforming biomedical information and health information access: Don Lindberg and the U.S. National Library of Medicine. Amsterdam: IOS Press; 2021.

[13] Mitchell JA. Donald A.B. Lindberg M.D. - my mentor. In: Humphreys BL, Logan RA, Miller RA, Siegel ER, editors. Transforming biomedical information and health information access: Don Lindberg and the U.S. National Library of Medicine. Amsterdam: IOS Press; 2021.

[14] Bashshur RL. Don Lindberg's wisdom and influence: a personal perspective. In: Humphreys BL, Logan RA, Miller RA, Siegel ER, editors. Transforming biomedical information and health information access: Don Lindberg and the U.S. National Library of Medicine. Amsterdam: IOS Press; 2021.

[15] Rain Tree D. Dr. Lindberg's mentorship. In: Humphreys BL, Logan RA, Miller RA, Siegel ER, editors. Transforming biomedical information and health information access: Don Lindberg and the U.S. National Library of Medicine. Amsterdam: IOS Press; 2021.

[16] West TG. Personal memories of Donald A.B. Lindberg, visual thinker and medical visionary. In: Humphreys BL, Logan RA, Miller RA, Siegel ER, editors. Transforming biomedical information and health information access: Don Lindberg and the U.S. National Library of Medicine. Amsterdam: IOS Press; 2021.

[17] Laylor J. Working with Dr. Lindberg: a personal perspective. In: Humphreys BL, Logan RA, Miller RA, Siegel ER, editors. Transforming biomedical information and health information access: Don Lindberg and the U.S. National Library of Medicine. Amsterdam: IOS Press; 2021.

[18] Thoma GR. Dr. Lindberg: an enduring source of inspiration. In: Humphreys BL, Logan RA, Miller RA, Siegel ER, editors. Transforming biomedical information and health information access: Don Lindberg and the U.S. National Library of Medicine. Amsterdam: IOS Press; 2021. 
[19] Phillips SJ. My journey with Donald A.B. Lindberg M.D. In: Humphreys BL, Logan RA, Miller RA, Siegel ER, editors. Transforming biomedical information and health information access: Don Lindberg and the U.S. National Library of Medicine. Amsterdam: IOS Press; 2021.

[20] Logan RA. Dr. Lindberg's talented assistant - an interview with Pat Carson. In: Humphreys BL, Logan RA, Miller RA, Siegel ER, editors. Transforming biomedical information and health information access: Don Lindberg and the U.S. National Library of Medicine. Amsterdam: IOS Press; 2021.

[21] Logan RA. Don Lindberg's home library and leadership traits. In: Humphreys BL, Logan RA, Miller RA, Siegel ER, editors. Transforming biomedical information and health information access: Don Lindberg and the U.S. National Library of Medicine. Amsterdam: IOS Press; 2021.

[22] Logan RA. Resources about Donald A.B. Lindberg M.D. In: Humphreys BL, Logan RA, Miller RA, Siegel ER, editors. Transforming biomedical information and health information access: Don Lindberg and the U.S. National Library of Medicine. Amsterdam: IOS Press; 2021.

[23] Logan RA, Lindberg MM. Don Lindberg: A photographic legacy. In: Humphreys BL, Logan RA, Miller RA, Siegel ER, editors. Transforming biomedical information and health information access: Don Lindberg and the U.S. National Library of Medicine. Amsterdam: IOS Press; 2021. 